University of East London Institutional Repository: http://roar.uel.ac.uk

This paper is the author's manuscript copy of a book chapter and is made available online in accordance with publisher policies. Please scroll down to view the document itself. Please refer to the repository record for this item and our policy information available from the repository home page for further information.

The final version is available to purchase from the publisher's website.

Author(s): Rustin, Michael

Article Title: Work Discussion: Implications for Research and Policy Year of publication: 2008

Citation: Rustin, M. (2008) 'Work Discussion: Implications for Research and Policy' Published in: Rustin, M., Bradley, J. (eds) Work Discussion: Professional Practice with Children and Families, Karnac Books 2008, pp 267-284.

Published version available to purchase from: http://www.karnacbooks.com ISBN: 9781855756441

Publisher statement: (not stated) 
Published in Work Discussion: Professional Practice with Children,

Adolescents and Families, edited by Margaret Rustin and Jonathan Bradley. Karnac (2008, pp 267-284).

\section{Work Discussion: Implications for Research and Policy}

\section{Michael Rustin}

The method of Work Discussion is highly particular - it depends usually on a single individual practitioner observing himself or herself usually while actively involved in work situation, and reflecting on the implications of what is seen and experienced. A Work Discussion seminar supervises and reflects on each member's observations and reports, and in that way there is a sharing of knowledge and understanding between practitioners whose work situations will usually have something in common. Nevertheless, it is the individual's experience of a situation which is the focus of exploration according to this method.

Work Discussion since its inception has had two major purposes. The first of these, which it shares with the method of Infant Observation, is educational and formative. It is intended, like infant observation from whose procedures it derives to a substantial degree, to enhance the understanding and capacities of those who undertake it as part of a programme of education in psychoanalytic ideas and methods, usually outside of or prior to their use by a the learner/practitioner in a clinical context. Its usual participants are students engaged in work in educational, health or care settings who are invited to conduct 'participant observations' in their places of work, and reflect on them in small seminars modelled initially on those which take place in Infant Observation programmes. The similarities lie in the method of presentation of detailed observational reports followed by supervisory and peer discussion, in the scale of the activity (ideally five or so seminar members in a group, permitting two presentations per student in each term) and in its continuity of experience (with participant observations preferably 
continuing for a year or more). This method has been found to provide an opportunity to observe, reflect on, and learn about the emotional and unconscious aspects of work-settings in educational, health and care settings which no other activity comparably provides. This has been a context in which some of the most valuable of contemporary psychoanalytic ideas could be learned in their use and application, and in their relation to experience, rather than merely 'learned about' as abstract concepts. Such complex ideas as those of the relations of containment, the mechanisms of splitting and projective identification, 'attacks on linking' (Bion 1962) and on thought, and the varieties of defences against unconscious anxieties, have through this form of learning become resources for understanding the dynamics of worksettings where human relationships are central. Just as with Infant Observation, it has been found that a combination of the experience-based learning of Work Discussion, with some parallel learning of relevant psychoanalytic concepts and theories, has enabled students to find meaning in emotional and unconscious aspects of their experience, and to achieve significant development in their capacity for thoughtful practice. In some educational programmes, Infant Observation and Work Discussion, sometimes Young Child Observation too, have been undertaken in parallel with one another, together with a supporting theory-based curriculum. The different balance between reflection and activity called for by these settings is often helpful to the learning process. ${ }^{1}$

For most of its history, the parallel method of Infant Observation has been conceived as a method whose main value is formative and educational - that is, in its development of the observer's capacities for understanding and feeling. While it was recognised early on that the presence of an infant observer was often found to be a good and even helpful experience by the mothers and families being observed, giving help to families was not its purpose. It was families without known problems or risks that were asked receive an observer - they were requested to help an inexperienced student learn about infancy, not to receive a visitor who was expected to advise or

\footnotetext{
${ }^{1} \mathrm{~A}$ broader discussion of the various linked components of the 'Tavistock method' of learning from experience is in Rustin (2003).
} 
teach them. It was quite late on in the development of this method that the idea that Infant Observation might be given an explicitly therapeutic purpose became recognised, and its possible application for the support of at-risk families tentatively explored. But it is clearly understood that this more 'therapeutic' conception of infant observation is quite distinct from its usual formative and educative purpose, and requires both a much greater previous experience on the part of observers, and a method of supervision with a focus different from a mainly educational one. While attention is given in 'normal' Infant Observation teaching to the emotional experience of the observation by the families - sometimes this reveals that this experience is appreciated by families and even found helpful by them - it is the student's learning experience that remains the predominant focus in the normal practice of noninterventive Infant Observation.

But with the method of Work Discussion, from the start, there could never be such a clear distinction between the purpose of learning from the point of view of the student, and the practical implications of the learning process for the work-settings which were being observed. The Work Discussion observers are also participants, often describing and reporting aspects of their own practice - they are not in this respect like the unobtrusive and nonactive visitors to a young family which is the normal practice of Infant Observation. They are invited to choose the situations they wish to discuss in Work Discussion seminars, and often these are situations selected by the participants-observers for the difficulties to which they are felt to give rise, for themselves as well as for others in their workplace. For example, teachers may present reports of their problems in their relationships with troubled children, or of tensions within a staff group; nurses may describe the painfulness of coping with the emotions aroused by distressed patients; careworkers the anxieties evoked by adolescents for whom they are responsible. Work Discussion seminars are often faced with the task not only of understanding what is going on, and the emotions and anxieties which are in play in a situation, but also of actively trying to help a participant-observer to cope better with a situation, and through this to enable practice to become a little more thoughtful. There is indeed sometimes an overlap, in the practice 
of Work Discussion, between the discussion of observational experience, and what is virtually a clinical supervision, since the practical work that is being reported and discussed may sometimes have a directly therapeutic aspect, as with art or drama therapists, counsellors, or many other 'care practitioners' who work directly with individuals or groups.

The consequence of this 'double purpose' of the Work Discussion method is that it has from the beginning been seen as a way of mapping the emotional and unconscious complexities of work-settings, and making possible new descriptions of these. This is not merely to facilitate the learning and personal development of student-observers, but can also have a more external or practical purpose. Participants in Work Discussion are often already experienced practitioners in their professional field when they enter this learning situation, even if psychoanalytic thinking as such may be new to them. It has therefore been reasonable to hope that a small improvement in the work of a specific work-group, or even a larger institution, might be the outcome even of a single individual's learning experience. As a contribution to professional formation, Work Discussion has thus come to be seen as a way of bringing about improvement in institutional practices through enhancing the capacities of practitioners, and the contributions to understanding which they can make. As a source of descriptions of hithertoneglected dimensions of relational or institutional processes, Work Discussion has contributed to the understanding of the ways that educational and care systems actually work, and provided new concepts and descriptions for understanding these. The origins of Work Discussion in work with General Practitioners by Michael Balint, referred to earlier in this book, is an early example of the value of a forerunner of this method for understanding a particular area of work. Work Discussion can be shown to make a difference through its implications for the work of an individual, in an otherwise conventional work setting but can also provide the basis for envisaging a new kind of institutional design. In this book, Alison Hall's chapter on her work as a nurse in a children's ward is an example of the first kind of application, and Simonetta Adamo and her colleagues' chapter on 'Parenting a new institution' is an example of the second. 
Work Discussion is indeed a method whose boundaries and extensions are porous and flexible. Those kinds of organisational consultancy which are informed by psychoanalytic thinking have long made use of methods of observation and reflection which are akin to 'Work Discussion'. Some of the concepts found most useful in it - for example the descriptions of institutional defences against anxiety developed in Menzies-Lyth's work - had their origin in the practice of organisational consultancy, but are learned and reflected on by new generations of practitioner-observers in Work Discussion settings. The consultation practices reported in The Unconscious at Work (Obholzer and Roberts 1994) and Working Beneath the Surface (Huffington and Armstrong 2004) are often close in their essence to what we describe here. In relation to schooling, Isca Wittenberg's The Emotional Aspects of Learning and Teaching (Salzberger-Wittenberg, Williams and Osborne 1983) sets out ideas which have become central to the agenda of Work Discussion for those working in educational settings. The approach described in Organisations

Observed (Hinshelwood and Skogstad 2000) is also congruent with what we present. Many professional training and development courses offered at the Tavistock and Portman NHS Trust, in disciplines which include social work, nursing, organisational consultancy, and educational counselling, have the Work Discussion method at the core of their curriculum. ${ }^{2}$

\section{Work Discussion and Research}

The question to be explored in this chapter is whether it may be possible to derive any implications of a more generalising kind, both for policy and research, from this method? Might Work Discussion prove as fertile as Infant Observation has done, in developing from what has been primarily a method of learning, into a source of new understandings of different fields of

\footnotetext{
${ }^{2}$ An earlier chapter has referred to the influential concept of ' practice' and the 'reflective practitioner' which has made an influential contribution to professional education, though without the primarily psychodynamic orientation of the Work Discussion method. (Schön 1991 and Atkinson and Claxton 2000.). These approaches, and those described here, both have affinities with philosophical approaches (Polanyi 1958, Toulmin 2001) which emphasise the role of tacit knowledge and attention to subjective experience in professional work, though the psychoanalytic approach has a substantial theoretical dimension.
} 
professional practice? What would it take for Work Discussion to become a method of research?

Researches in different fields are necessarily different and distinct from one another: many errors and confusions arise from presuming or demanding that all research activity should conform to a single template. Researches differ, in what they postulate as their object of study, and in the methods of perception and measurement appropriate to them - that is to say in their implicit ontologies and epistemologies. They differ in the means by which they typically represent or communicate their findings - what Bruno Latour (1987) terms their 'inscription devices'. Thus maps are important to geographers, fossil records to palaeontologists, statistical correlations to epidemiologists, social surveys to (some) sociologists, and clinical ase-studies to psychoanalysts, because of the distinctive attributes of the findings they seek to report, and forms of representation which follow from these attributes. Research fields usually also have distinctive communities of reception and understanding - their findings are usually addressed primarily to specialists qualified to understand and assess them, and perhaps to practitioners or policy-makers whose work they are intended to inform. The understanding that there is not one science, but many (though with some important shared principles of respect for logic, for impartiality, for evidence, for empirical testability, and for reliability) has been one of the most important insights which has followed from Thomas Kuhn's seminal The Structure of Scientific Revolutions (Kuhn 1962 and 2000), and has been adumbrated and extended by a whole generation of subsequent contributors to the sociology of science and technology. (Galison and Stump 1996) .

The field of Work Discussion, as it is set out in this book, is primarily an application of psychoanalytic ideas and methods to the emotional and unconscious life of the organisational settings in which work with children and young people takes place. In so far as its orientation is psychoanalytic, its distinctive objects of study are unconscious mental and emotional processes. The non-transparency of unconscious processes, to participants but also often in the first instance to observers, gives rise to distinctive observational 
difficulties. It is after all because unconscious mental processes are unconscious, and because understanding of them is sometimes resisted by both individual and collective subjects, that they are difficult to observe and take account of, yet may also be potentially powerful and disruptive. It is often just because of such disruptive and disturbing effects on both individuals and groups, that there is sometimes felt to be the deep wish to understand them. The need to understand phenomena of this kind provides the essential motivation of the Work Discussion method as we describe it. ${ }^{3}$

Psychoanalytic methods have evolved over decades as the most powerful means of investigation of this 'unconscious' dimension of reality, and the carefully-designed and moderated setting of the clinical consulting room has been its primary instrument of observation. (Rustin 2002, 2007). The investigation of the phenomena of the transference, and more recently the counter-transference, and the discipline of detailed and meticulous descriptive report of all that happens in the clinical setting, for subsequent reflection and analysis, are its principal investigative resources. Many of the theoretical ideas found most useful in Infant Observation and Work Discussion have their origin in discoveries made in the clinical consulting room. The clinical case study has been the primary form of representation, or 'inscription device' of this form of investigation. There has been much criticism of the unreliability and 'subjectivity' of clinical reports as a source of data, (e.g. by Spence 1983, 1994) though now it is being shown that it is possible to improve on informal clinical methods of analysis of clinical data, through more rigorous and systemic modes of analysis. It should become possible to achieve higher

\footnotetext{
${ }^{3}$ 'Work Discussion' as described here has a predominantly psychoanalytic focus of interest. It does seem likely however that the method of close participative observation of work-settings, with regular supervised peer discussion of reported observations, could be undertaken from other disciplinary perspectives, for example those informed by sociological or anthropological conceptions. Observational methods with a more pedagogic focus have long had an important role in teacher education and professional development, where they have also been assigned a research purpose. (Blythman and Macleod 1989 give a summary with a useful bibliography, Hammersley 1993 explores research issues.) What the observation method, and especially Work Discussion, usually encourages is a process of learning inductively from particular situations, drawing on definite conceptual and theoretical resources as sources of meaning and connection, while still allowing individual experience its own interpretative freedom. There are ways of understanding psycho-social and institutional interactions other than those captured by psychoanalysis which could be developed by this participant observational technique .
} 
standards of validity and reliability in developing theories and classifications from such data. But in any case one must keep in mind that the development of the conceptual and theoretical lexicon of psychoanalysis has been a highly successful one. The power and scope of psychoanalytic explanation has greatly increased during the hundred-years long history of psychoanalytic investigation, even though for most of its history it has relied to achieve this on the 'craft skills' of clinical interpretation of data obtained in the consulting room setting, which have themselves been subject to refinement and development in relation to the extension of the field of study. (In many if not most fields of knowledge, advances in substantive knowledge are necessarily linked to advances in the techniques by which knowledge is acquired.)

It is to be expected that applications and extension of psychoanalytic clinical methods, such as those of Infant Observation, or of Work Discussion, will share many of the core attributes of this 'parent' clinical method. Likely to be fundamental to knowledge-generation in these organisational and relational settings are procedures of detailed descriptive reports, an attitude of respect for particulars, the grounding of theoretical inference in detailed instances, and the testing of interpretative findings through critical reflection by independent participants, which are also central to psychoanalytic clinical methods. And these are indeed the practical disciplines which participants in Work Discussion (as in Infant Observation) are expected to learn, in the development of their own observational and interpretative capacities.

Where knowledge is primarily advanced through the accumulation of theoretically- informed descriptions of situations, and through the discovery of 'kinds' of phenomena found to share the same characteristics (in psychoanalytic thinking, these may for example be pathological states of mind, or psychic defences, or phases of development) systematic comparison between instances is essential. Research based on the case-study method in psychoanalysis has advanced through such a process of comparison between case-examples, often following the postulation in the psychoanalytic literature of some new or hitherto unrecognised phenomenon, which has then become the focus of further investigation by practitioners. We can trace the 
development of many of the most significant concepts in psychoanalysis from such a key initial presentation of an original idea, through its exemplification and testing-out in many other instances. ${ }^{4}$ Sometimes such investigation has been given a relatively organised form, through the practice of clinical workshops which may retain a common focus of interest and attention for a lengthy period. (M.E. Rustin 1991). Sometimes the context of theoretical development has been less publicly visible, either because the work of an individual analyst has been decisive, or because communication between coworkers has been more informal. Generally it has been the case that the procedures of data collection and data analysis which have been followed in the clinical tradition have depended on a high degree of 'craft skill' or 'practical knowledge' on the part of practitioners, rather than on the use of formal protocols, though there are exceptions, and there is now a significant change taking place in the direction of a limited degree of formalisation of research methods. The development of university doctoral programmes in the psychoanalytic field has been one significant catalyst of this move towards formalisation and greater methodological accountability.

It has been shown that the method of Infant Observation, designed originally as an experience of learning, also has potential as a form of psychoanalytic research. The understanding of parent-infant relationships has been significantly enhanced through the findings of Infant Observers. In particular, the detailed exploration of the idea of 'containment' in the mother-baby relationship, and of the probable outcomes of different forms of containment, more and less favourable to development, has become influential in the field of infant mental health and to the psychoanalytic understanding of children and families more generally. It seems possible that the original development of the container-contained relation drew not only on Bion's seminal inferences from his clinical experience with psychotic patients, but also on the observational and analytic experience of the early pioneers of Infant Observation, notably Esther Bick. It has been argued elsewhere that there is

\footnotetext{
${ }^{4}$ On the development of psychoanalytical knowledge (mainly in Britain) from this perspective see Rustin 2007 and 2008, and Judith M Hughes 2004.
} 
scope for a more sustained deployment for purposes of research of the Infant Observational method, though this would require some change from the conventional 'learning' practice of observations mainly of the spectrum of 'normally functioning' families undertaken by Infant Observers with no previous experience of the field. (Rustin 2006)

But the method of Work Discussion may have an even greater potential than that of Infant Observation for utilisation as a method of research. This is because of the significant measure of professional and institutional knowledge that some practitioner-observers bring to this work from the outset. And also because as practitioners, participants in Work Discussion are in a situation which enables them to actively explore and test out the hypotheses that they may formulate, giving an 'action research' dimension to some practices. ${ }^{5}$ There are examples in chapters in this book of new patterns of activity being developed in settings for work with children, whose outcomes are made the subject of clear description and even a measure of informal evaluation. Such concepts such as those of defences against anxiety, organisational splitting mechanisms, containment (or its lack), and benign and malign kinds of group formation (the contrast made by Gianna Williams between gangs and groups, for example) can be seen to do valuable explanatory work in descriptions offered in this book. Concepts like this - and one can add, 'borderline states of mind' or states of organisational mindlessness - here serve as descriptions - even 'diagnoses' - which can be seen to be more widely recognisable or typical of what happens when institutions and groups are subject to stress. On the more positive or proactive side, is the idea that reflection on emotional experiences can make a difference to the quality of a human service. Indeed the creation of space for such reflection, whether on a person-to-person (e.g. nurse-to-patient) basis, or a broader institutional setting, is often what these participant-observers attempt to make possible, as their distinctive

\footnotetext{
${ }^{5}$ A significant difference between clinical practice and Infant Observation from the point of view of research is the opportunity that clinical practice affords for analysts to be active in exploring conjectures and hypotheses, through interpretations and the understanding of what comes of them in a session. By contrast, the largely passive role prescribed for Infant Observers precludes them from such active exploration in their observation setting. (Rustin 2006). Work Discussion lies somewhere between these two methods in this respect.
} 
contribution to their work setting. Work Discussion is both the scene of a form of reflection initially outside the work context, yet also provides some kind of exemplary model of a kind of interaction which would be usefully taken up within it. The chapter by Simonetta Adamo and her colleagues describes how something like 'Work Discussion' has been formative in the design and operation of a new although small institution, providing a therapeutic form of schooling for adolescents in Naples who were previously wholly absent or excluded from school.

From the point of view of knowledge-generation, it is a weakness of the Work Discussion method that the settings whose work is described and reflected tend to be very different from one another, and therefore hard to compare. Such institutional contexts may depend simply on where the participants in a Work Discussion programme happen to be working. There are, however, advantages in seminar participants being able to think together about very different settings. They can for example learn about that key concepts and ways of understanding can have a wide application, well beyond their own personal experience, to work-situations that might otherwise have seemed to have few similarities. There are certainly some benefits to be gained from Work Discussion seminars whose members do not come from the same workplace, since this avoids the potential problems of confidentiality, and unwanted feedbacks between what takes place in the reflective space of the seminar and what might then have to be dealt with on a daily basis back at work.

But from a research perspective, one can see advantages in varying the common practice of bringing participant observers together from work settings of different kinds. One can conjecture that more systematic investigation of a particular kind of institutional context (e.g. hospital wards, classrooms, care homes, social service departments) would proceed more easily if Work Discussion seminars were composed of members who were all drawn from such a setting, rather than being assembled in a more random way. Comparison between observations, and between 'experimental initiatives' , each made within a distinct kind of workplace (e.g. a school or a prison) 
could facilitate the development of understanding, just as has the consideration of similar kinds of phenomena in clinical workshops in child psychotherapy. It would also be interesting to compare the outcomes of the Work Discussion method when it is practised by participants drawn from different institutions (whether in the same field of provision or not), with its practice when participants share an institutional workplace. The former approach places the main responsibility for learning on the individual participant, the latter requires a group of participants to understand and take responsibility not only for their interactions within the separate space of the Work Discussion seminar, but also 'back home' in their normal work situation. The understanding of the outcomes and implications of these different uses of the Work Discussion method can only be learned about from experience and comparison.

It would assist the generation of knowledge by means of the Work Discussion method if a 'lexicon' of the concepts and theories which have been found most productive for these understandings, and a literature of studies or cases in which such ideas have found an explanatory use, were assembled and documented. There is scope too for the development of more formalised and accountable methods of analysis of the descriptive reports on which Work Discussion is based, for example making use of the methods of Grounded Theory appropriately adapted to this task. In some practitioner-observer settings it might be possible to audio-record and transcribe particular interactions (records of meetings for example ${ }^{6}$ ) although often reliance will have to continue to be made on post-facto written records. But it may certainly be possible to record the proceedings of Work Discussion seminars, in order to better understand the processes of inference from primary observational data which emerge in such seminar settings. There thus seem to be several ways in which has hitherto been a rather informal, though meticulous process of data-gathering, transcription and analysis, could become more systematic, transparent, and accountable.

\footnotetext{
${ }^{6}$ Two doctoral researchers in social work at the Tavistock Clinic, Philippe Mandin and Vimala Uttarkar, are making use of such recordings in their work.
} 
In order for Work Discussion to become a recognised and productive location for research, it has to be thought of in these more systematic terms, and some adaptations made to its procedures. This would only be to follow a pattern of development which occurred long ago in the clinical practice of psychoanalysis, and more recently, in the last two decades or so, in the practice of Infant Observation. Such a development would make it possible for Work Discussion to generate sustained and credible descriptions of the interactive processes, conscious and unconscious, which are its distinctive fields of study. There thus seems to be scope for the development of the existing 'formative' and 'capacity building' method of Work Discussion into a method of research whose findings could demonstrate the explanatory power of a psychoanalytic ways of thinking when it is applied to many kinds of 'outdoor' or extra-clinical settings.

Such studies, in so far as they remain within the broad parameters of Work Discussion as it has been described in this book, are likely to be primarily qualitative in their form. There is a different and of course important form of research, which sets out to test in a statistically robust way the outcomes and effects of different processes or indeed interventions. This is the kind of research approach which dominates current discussions about the 'evidence base' of practice. But before there can be a useful quantitative test of a theoretical formulation, or of a proposed form of intervention, there needs to be a theoretical formulation or interventive design which is interesting and descriptively-grounded enough to be worth the effort and cost of quantitative measurement, on the scale which this usually requires to achieve validity and reliability. But it need not be seen as a problem if in the early stages of the development of Work Discussion as a research method, it is seen as belonging to the 'context of discovery' - a source of generative new ideas rather than to the 'context of validation' of new knowledge - the process of establishing scope, applicability and, so far as interventions are concerned, cost-effectiveness. The former stage most often precedes the latter in a

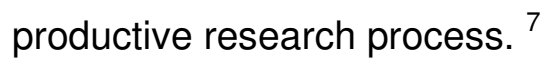

\footnotetext{
${ }^{7}$ On contexts of discovery and validation see Rudner 1966
} 


\section{Work Discussion, Policy and Practice}

'Evidence-based policy' and its performance measures

There is a strong emphasis in contemporary government policy-making and implementation on 'evidence-based policy'. This usually involves establishing measures of current performance of public sector institutions - e.g. schools, hospitals, university departments - to bring about improvements in performance through clearly specified interventions, whose aims are often formulated as 'targets.' Alongside this is guidance about practice, such as that provided for clinical services by NICE (the National Centre for Clinical Excellence) about those treatments with the strongest evidence-base.

Examples of such performance measures are waiting lists for NHS care, assessed numeracy and literacy scores in primary education, and the time taken to achieve permanent placements for looked-after children. Such measures sometimes come to be regarded as proxies for broader conceptions of service-quality. The case which has recently been argued for making Cognitive Behaviour Therapy available as the treatment of choice for adults suffering from depression (Layard 2005) is based on reported evidence for the remarkable efficacy of this form of therapy, evidence which is however disputed particularly in regard to the more severe and persistent kinds of depressive condition.

There are risks that the adoption of such measures as the criteria by which the performance of institutions will be judged, , even when they are inherently reasonable, can have perverse effects, giving undue priority to specified dimensions of an institutional task which seem amenable to exact measurement, at the expense of other aspects which may be harder to 
calibrate, but which may in reality be more fundamental. ${ }^{8}$ 'Evidence-based policy' now unfortunately pays little attention to practice-based evidence.

This is even more the case when the aim is not only to set out specific performance criteria to guide managers and practitioners in their work, but also to provide measures for judging the comparative performance of institutions, expected to operate in a virtual competition with one another, whose outcome is reported in published league-tables. ${ }^{9}$ Such competitive outcomes carry with them rewards (such as a lessened liability to inspection, or greater attractiveness to prospective clients or employees) for those deemed more successful, and sanctions for those deemed less successful (such as intensified regimes of inspection, the removal of managers, or the closure or take-over of whole institutions). In these cases, selected performance measures come to be perceived as indicators of a more general worth or status. While these ratings may be incentivising for the more successful or advantaged, they may also be demotivating for the less successful and disadvantaged, increasing rather than decreasing disparities of performance between institutions and their client populations. Preoccupation with the outcomes of such competitive judgement may certainly divert practitioners, and perhaps their clients too, from the primary goals of the services in question, substituting extraneous for intrinsic measures of quality. Sometimes, in fact, the organisational climate which emerges in response to anxieties about meeting prescribed targets may worsen the quality of what is provided.

In seeking methods of defining performance in terms which lend themselves to measurement, the application of rewards and sanctions, and the creation of regimes of competition, 'the new public management' (Clarke et al. 2000) has been seeking to find proxies for the largely standardised and replicable measures of turnover and profit which are regulative in market competition.

\footnotetext{
${ }^{8}$ Such diversionary or perverse effects have been pointed out in critiques of contemporary audit systems, for example in Power 1994, Strathern 2000, Rustin 2004, Travers 2007.

9 Sometimes, in an act of official hypocrisy, the 'league tables' are held to be the responsibility of press reporting rather than the audit process itself, even though everyone knows that it is these tables that have the most significant consequences for institutions.
} 
The aim is to find a way of translating qualities into quantities, so to speak, just as financial accounting translates the qualities of supermarkets, theatre performances, or novels, into sales figures and ultimately into profit measures. The purpose of such performance criteria may be to find the nearest feasible equivalent to an accountable bottom line which is represented by the balance sheet of a firm in the market. Of course, in addition to these measures of service-quality or user-satisfaction, financial balance sheets have also become critical measures of performance in public sector institutions. Since these institutions are often now located in various kinds of quasi-markets (for patients, students, placements etc.) and incomes often follow 'customer choice' between service-providers, equivalents to market-regimes within the public sector have widely been created. Since it is desirable that public services should improve, and that managers and users should to be able to compare the performance of different providers, such forms of measurement seem to be useful and necessary. Without common measures, it is difficult to make meaningful comparisons.

Something however which preoccupies many workers in public services especially those in which human relationships make an important contribution to the quality of a service, is whether performance indicators of this kind adequately measure the quality of a given service. They are often believed to leave out of account some of the most important dimensions of the experience of the clients of services, and of those who deliver them. It is to these 'missing areas' that the methods of Work Discussion usually address themselves.

\section{Relationships in Work Settings}

Reflective Work Discussion, and the kinds of work practices and sensitivities it seeks to enhance, has a conception of interpersonal work, especially in the caring and educational services to which it has been most often applied, which contrasts with a dominant managerial focus on measurable targets and outcomes, while not necessarily disputing the value of these for improving service-quality. Its emphasis is on the human relationships within which these kinds of work take place, and on the quality of interactions and communication 
that take place in work-settings. Its particular interest is in the unconscious emotional dynamics which are inseparable from many work situations, especially in the domains of education, health and welfare.

The guiding assumption of this method of learning is that the provision ${ }^{10}$ of human services nearly always takes place in the context of a significant relationship between provider and client. The relationships between teachers and pupils or students, nurses or doctors and patients, social workers and clients, policemen and citizens whose behaviour they are seeking to keep within acceptable bounds, are examples of such kinds of relationships. There can be no good delivery of human services, this perspective holds, without a relationship capable of holding and giving appropriate meaning to what is being provided.

As we have suggested earlier, Work Discussion has been conceived as an intervention intended to improve professional practice almost since its inception. This purpose arises from its fundamental conceptions. These include the idea that high-quality work in the educational, health and caring fields has a crucial 'relational' dimension, and that the 'holding in mind' of intense states of feeling is a precondition of good institutional practice. To achieve this, the capacity to relate in appropriately understanding and sensitive ways to patients, pupils, clients and colleagues, and to be able to bear the stresses of occupational anxiety, need to be developed by individuals, as well as nurtured by appropriate kinds of supervision and management. Work Discussion aims to develop these human capacities, and its advocates believe that such development can lead to broader changes in occupational practice, often in a very local way, but sometimes more broadly if there is receptiveness to these approaches within a larger institutional setting or occupational tradition.

\section{Holding in Mind}

\footnotetext{
${ }^{10}$ More widely used these days is the concept of 'service-delivery', whose function is to impose a mode of thinking appropriate to commodity distribution on to transactions in which relationships are usually a primary consideration, rather than a secondary one, as in transactions in a supermarket.
} 
The Work Discussion method, as we have seen earlier, has been strongly influenced by the psychoanalytic conception of containment developed by Wilfred Boon and others. The development of the personality in infancy depends, according to this account, on relationships in which the intense feelings and anxieties which are an inescapable part of human growth can be adequately recognised, borne and understood. Bion's, and Winnicott's parallel account, holds that such feelings are, when all goes well, 'processed for' the growing infant by its mother or carer, enabling the infant not to be overwhelmed by them. Where an adequate quality of containment is not available, or where care takes actively invasive or harmful forms, anxieties rise to an abnormally high level, and defences may be created to deal with these which are ultimately damaging to emotional development and the capacity to sustain relationships in which love and trust predominate.

The theoretical perspective which underlines the method of Work Discussion has extended the conception of containment explored systematically in Infant Observation in the relationships of early infancy, to broader contexts of relationship outside the family. Intense emotions and anxieties, explicit or latent, conscious or unconscious, do, it is held, pervade the relationships which individuals form with the institutions on which they depend in significant areas of their lives. Wherever individuals find themselves dependent on the attention and care of others for their well-being, the potential for intense emotion and anxiety will be evoked, and will find itself as a dynamic if often unrecognised aspect of a work-situation. The kinds of situation which the practice-observations of this book report are those where relationships are created between 'service providers' and 'users' in which a considerable intensity of feeling, need or desire is often invested. This is different from work situations in which more short-term or casual exchanges between relative strangers are the norm, as in many kinds of commerce or public setting, although we know that these can also evoke strong and anxious feelings when they take an unexpected turn. 
Relationships between colleagues in work settings also have this dimension. Relations at work are a major source of many individuals' identity and sense of worth, and of their ongoing human connectedness. ${ }^{11}$ This is the case whether or not the primary task of an organisation in which individuals work is concerned with relationships of care. Some of the insights to be derived from the Work Discussion method are therefore likely to be applicable to work situations of all kinds.

One of the beneficial outcomes of Work Discussion as a method of learning is to enhance practitioners' capacities to observe and respond in sensitive ways to emotionally charged and complex situations. Practitioner-observers with this experience learn to notice and take in what would formerly have passed them by. They learn more tolerance of unavoidably painful situations, become better able to understand the pain and anger of those they are working with. They become more likely to see constructive and creative solutions to apparent impasses in work with clients or colleagues, and less likely to respond by flight or by countering aggression with aggression. The papers in this volume show many examples of such thoughtful and creative responses to work situations full of difficulty.

\section{What can be learned from Work Discussion?}

How then might Working Discussion become a means of improving professional practice and policy-making, aside from its desirable use as part of 'continuing professional development' or CPD programmes? How can this method of 'learning from particulars' come to have a broader influence?

It is clear that making available fuller and better-documented descriptions of institutional contexts and practices from reports based on the Work Discussion method, can enhance understanding. Such accounts, as have seen in this book, can provide compelling evidence, especially when they give

\footnotetext{
${ }^{11}$ On the changing relationships of work, see Richard Sennett 2000 and 2006.
} 
meaning and shape to the experience of the providers or users of the services they describe. One should recall that different forms of knowledge not only usually have their distinctive objects and methods, but also their distinctive communities of reception. The communities of reception in the case of Work Discussion include practitioner communities, and a larger public, as much as specialists in the social and psychological sciences.

It is important to note that the kinds of research which have lasting influence are not always those which depend on the quantitative scale of a demonstration. As Rom Harré (1993) has pointed out, in his defence of 'intensive' in contrast to 'extensive' methods in the human sciences, much investigation even in the natural sciences has proceeded from the study of particular instances, by which, as in a crucial experiment, a broader theoretical conception is put to the test. The discovery high up on mountainsides by Darwin of the fossilised remains of creatures which must once have lived in the sea, was compelling evidence of a process of evolution over time, even when only a few such fossils had been discovered. It only needs the demonstration that one species can live and reproduce itself miles beneath the sea, in the absence of any light from the sun but taking its necessary energy from deep-sea volcanic action, to refute the idea that all living creatures depend on solar energy. The distresses and disturbances of quite small numbers of young children, deprived of the proximity of their parents or other familiar carers in hospitals, or removed from any attentive care in orphanages, have given ample evidence of what young children need to thrive. In the latter case, the 'inscription device' of documentary films, (those of James and Joyce Robertson) were powerful additions to the observed and written-up study of what had happened to the children. And it appears that the observation of the autistic behaviour of children abandoned in neglectful nurseries in Romania has been taken as decisive evidence against an exclusively genetic explanation of autism.

But while numbers are not always decisive, in the first instance at least, the accuracy and perceptiveness of a description, and its being framed in concepts which name what is essential, is. We might hope that quite small- 
scale studies based on practitioner-observer experience, could change our understanding of work-situations and their needs, if they were well-enough focused and described.

There is scope for the Work Discussion method to have some influence on institutional design too, but in this respect we are at a fairly early stage of development. For this, the conditions for a more systematic approach to institutional research need to be met, including the engagement of more experienced researcher-practitioners, a focus on selected contexts of work e.g. day nurseries, infant schools, children's wards, university classes, remand centres - and more accountable methods of data collection and analysis. ${ }^{12}$ Demonstrating the value of a psychoanalytically informed approach to institutional practices - the underlying commitment of Work Discussion - depends on the generation of compelling descriptions of the differences between institutions and practices which are able to reflect with understanding on the functions of emotions, relationships and anxieties in their work, and those which are not. Several descriptions of this kind are offered in this book, and we hope that many more will follow.

\section{References}

Atkinson, T. and Claxton T. (eds) (2000) The Intuitive Practitioner: on the value of not always knowing what one is doing. Open University Press.

Bion, W.R. (1962) Second Thoughts. Heinemann.

Blythman, M., and MacLeod, D. (1989) Classroom Observation from Inside. Spotlights 16, Scottish Council for Research in Education. Find at scre.ac.uk/pdf/spotlight/spotlight16.pdf

Clarke, J., Gewirtz, S., McLaughlin, E., (eds) (2000) New Managerialism, New Welfare? Sage.

Galison, P. \& Stump, D.J. (ed) (1996). The Disunity of Science. Stanford: Stanford University Press.

\footnotetext{
${ }^{12}$ Ongoing work for professional doctorates being undertaken at the Tavistock and Portman NHS Trust in Social Work, Child Psychotherapy, Systemic Therapy and Organisational Consultancy currently involves studies in several of these settings.
} 
Hammersley,M. (ed) (1993) Controversies in Classroom Research. Open University Press.

Harré, R. (1993) Social Being. ( ${ }^{\text {nd }}$ edition). Blackwell.

Hinshelwood, R.D. and Skokstad, W. (eds) (2000) Observing Organisations: Anxiety, defence and culture in health care. Routledge.

Huffington, C., and Armstrong, D. (2004) (ed) Working Beneath the Surface: the Emotional Life of Contemporary Organisations. Karnac.

Hughes, J.M. (2004) From Obstacle to Ally: the Making of Psychoanalytic Practice. Hove: Brunner-Routledge.

Kuhn, T.S. (1962) The Structure of Scientific Revolutions. Chicago University Press.

Kuhn, T.S. (2000) The Road Since Structure: Philosophical Essays 19701990, with an autobiographical interview, eds. James Conant and John Haugeland, Chicago University Press.

Latour, B. (1987. Science in Action : how to follow scientists and engineers through society. Milton Keynes : Open University Press.

Layard, R. (2005) Happiness: Lessons from a New Science. Allen Lane/Penguin.

Menzies Lyth, I. (1959) 'The Functioning of Social Systems as a Defence Against Anxiety', in Human Relations 1959, reprinted in I. Menzies Lyth Containing Anxiety in Institutions, Selected Papers Vol. 1. Free Associations Books 1988.

Obholzer, A., and Roberts, V.Z. (eds) (1994) The Unconscious at Work. Routledge.

Polanyi, M. (1958) Personal Knowledge:Towards a Post-Critical Philosophy. Routledge and Kegan Paul.

Power, M. (1994) The Audit Explosion. Demos.

Rudner, R. (1966) Philosophy of Social Science. Englewood Cliffs NJ: Prentice Hall. 
Rustin, M.E. (1991) 'The strengths of a practitioner's workshop as a new model in clinical research,' in S. Miller and R. Slur (eds.) Extending Horizons. London: Karnac.

Rustin, M.J. (2002) Give me a consulting room: the generation of psychoanalytical knowledge,' in Reason and Unreason, Continuum Books.

Rustin, M.J. (2003) 'Learning about emotions: the Tavistock approach.' European Journal of Psychotherapy, Counselling and Health pp 187-208.

Rustin, M.J. (2004) 'Rethinking Audit and Inspection', Soundings 26, Spring pp 86-107.

Rustin, M.J. (2006) Infant observation research: What have we learned so far? Infant Observation, 9, 1. 35- 52.

Rustin, M.J. (2007) 'How do psychoanalysts know what they Know?' in L. Braddock and M. Lacewing (eds.) The Academic Face of Psychoanalysis. Routledge.

Rustin, M.J. (2008) 'What do child psychotherapists know?' in Nick Midgley, Jan Anderson, Tanya Nesic-Vuckovic and Cathy Urwin , eds. Child Psychotherapy and Research: New Approaches, Emerging Findings. Routledge.

Salzberger-Wittenberg, I., Williams G., Osborne, E. (1983/1999) The Emotional Aspects of Learning and Teaching. Routledge Education Books, reprinted Karnac. Karnac.

Schön, D. (1991) The Reflective Practitioner: How Professionals Think in Action. (new editition). Ashgate.

Sennett, R. (2000) The Corrosion of Character: the Personal Consequences of Work in the New Capitalism. Norton.

Richard Sennett, R. (2006) The Culture of the New Capitalism. New Haven, Conn. Yale University Press.

Spence, D. P. (1983) Narrative Truth and Historical Truth: Meaning and Interpretation in Psychoanalysis. New York: W.W. Norton.

Spence, D.P.(1994) 'The special nature of clinical facts.' International Journal of Psychoanalysis Vol. 75, Part 5/6, pp- 915-927.

Strathern, M. (ed). (2000) Audit Cultures: Anthropological studies in accounting, ethics and the academy. Routledge.

Toulmin, S., (2001) Return to Reason. Harvard University Press. 
Travers, M. (2007) The New Bureaucracy: Quality assurance and its critics Policy Press. 